First publ. in: International encyclopedia of the social and behavioral sciences / Neil J. Smelser and Paul B. Baltes (eds.). Oxford: Elsevier, 2001, pp. 3003-3007

\title{
Cross-cultural Study of Education
}

Results of educational research from Western cultures may not be universally valid. Extending research to other cultures may reveal relevant phenomena and processes and allow the specification of universals and culture specificities as influenced by genetic and environmental factors relevant to development and learning. 
Education is understood here as cultural transmission resulting from enculturation and socialization in informal or formal learning contexts. It includes intentional and unintentional influences on a person's thinking and behavior. Culture is not conceived of as a set of independent variables 'outside' of education influencing people in a unidirectional and unavoidable way. Culture is understood here as a certain commonality of meaning, customs and rules (not a homogeneous entity) shared by a certain group of people and setting a complex framework for learning and development.

\section{Formal and Informal Education}

Formal and informal educational contexts are of special interest for studies on education. Both contexts provide opportunities for and constraints on individual learning and development. These may function in different ways, depending on the cultural context.

\subsection{Differentiation of Formal and Informal Education}

Formal education, following the 'Western model,' consists of systematic instruction in 'universal' knowledge and skills, provided at prearranged times and places by specialists. Formal education also exists as indigenous education including initiation ceremonies, instruction provided in age-grade societies, and various forms of religious schooling, such as Quranic schools. There are cultural differences in the institutionalization of formal education, e.g., in the organization of the educational system, the relation between public and private schools, the length of compulsory schooling, the number of years of elementary and secondary schooling, the school curriculum, teaching, and instruction.

Informal education includes life-long socialization influences from interacting, e.g., with family members or peers in settings related to culture-specific values and norms useful for everyday experience. In all cultures, education takes place informally in everyday situations, in response to momentary needs, and sometimes simply involves observation and imitation (for a summary, see Segall et al. 1999, pp. 78-88). Informal traditional education including moral and spiritual aspects as well as manual labor, is in essence adapted to the local cultural system which it tends to perpetuate. According to Désalmand (1983), characteristics of traditional (African) education as compared with schooling are as follows: it is provided everywhere, all the time, and by everyone; it is closely tied to the environment, integrated with productive work, and addresses the needs of the society. It emphasizes cooperation rather than individual com- petition; everyone can be successful. Parents and elders play an important role, relations among participants are personalized, and occurs in the local language.

As Bruner (1996, p. ix) remarks: 'Schooling is only one small part of how a culture inducts the young into its canonical ways. Indeed, schooling may even be at odds with a culture's other ways of inducting the young into the requirements of communal living.'

\subsection{Transmission of Know-how in Informal Education}

1.2.1 Apprenticeship. An essential process in informal education is apprenticeship. Informal education can transmit specific, economically useful knowledge and often follows a very structured, albeit implicit, pedagogy. This was demonstrated in Greenfield and Lave's (1982) study of weaving apprenticeships among Zinacanteco girls in Mexico and tailoring in Liberia. Masters employ scaffolding to effect a progression within each step, allowing trial and error only if there is no material risk. Informal education thus involves more than just observation and imitation. Verbal instruction is an integral part of the apprenticeship process, but the pupils seldom speak and do not ask questions.

Based on her studies with Nahua Indians of Mexico, Chamoux (1986) provides a typology of know-how (or skill) and its transmission that distinguishes between 'incorporated know-how' and 'the mastery of algorithms.' The former results from personal, concrete experience; one may have a certain skill but not be able to describe it. It is therefore not easily transmitted by formal teaching and is best acquired through apprenticeship, i.e., by participating in the activity.

Incorporated know-how may be general or particular, i.e., transmitted to everyone or only to certain individuals who become specialists. Transmission occurs either with a master or through gradual immersion; the latter is possible in the case of cultural activities that can frequently be observed.

1.2.2 Ethnotheories. 'Indigenous theories of education' structure the pedagogical modalities in a coherent fashion (Chamoux 1986, Super and Harkness 1997). In some types of traditional informal education (e.g., for Nahuas), observation is preferred to instruction as a learning method, and may be combined with low pressure to learn and high preference for the will of the apprentice.

1.2.3 Guided participation in cultural activity. The way caretakers structure the activities of children is 
another characteristic, studied by Rogoff et al. (1993), who observed caregivers and their toddlers in four settings: Mayan Indians in a small town in Guatemala, a tribal village in India, and two middle-class urban neighborhoods in Turkey and the USA. In the first two communities, children were nonverbally encouraged to observe adult activities; they were basically responsible for their own learning. In the two middle-class settings, mothers tended to structure explicitly their children's learning, used verbal interactions, and provided 'lessons' removed from the context of ongoing activities. They also tended to organize their schedule to separate adult activities from time devoted to interacting with children. In the two rural communities, adults shared their attention among a variety of activities, managing several tasks at the same time, including socializing with other adults and facilitating the children's involvement and learning. The behavior of the middle-class mothers can be seen as a preparation for schooling. Rogoff et al. (1993) suggest that many school reforms move in the direction of group work in which the children become more responsible for their own learning.

\subsubsection{Schooling and apprenticeship. The transferab-} ility between practical and school-based knowledge is of special importance in education research. Delbos and Jorion (1984) observed how empirical knowledge is conveyed in traditional professions in France in contrast to scientific, school-based knowledge. In activities where competence is acquired through experience within the family, knowledge is transmitted not explicitly but through participation in daily life and as if it were an unquestionable truth. While this knowledge is specific, school knowledge is rather general and abstract but transferability does not always live up to the facts.

\section{Educational Effects}

One aim of education research is to specify conditions for development and learning. However, it is difficult to derive general conclusions on the basis of only Western-world theorizing and methodology.

\subsection{Effects of Different Educational Systems}

What are the effects when an educational system is implanted into another culture? The export of Western-type schooling into 'traditional' societies is often criticized because of its lack of cultural relevance and practical use. Julius Nyerere (1967) (a former President of Tanzania and also a teacher) was one of the first critics. Serpell and Hatano (1997) provide excellent coverage of the inportation of Western-type schooling during colonial times (in what they call hegemonic imposition') and summarize the present situation for Africa: 'The entire design of public schooling in Africa tends to bear very little relevance to the demands of economically productive adult life in rural settings, where the vast majority of school-leavers will spend their lives' (p. 363)

In contrast, Kagitçibasi (1996) points out the many positive effects of schooling, notably in terms of health promotion and women's rights, and is concerned that critiques of schooling may impede the implementation of policies to attain the UNESCO goal of "education for all.'

Effects of formal and informal education are difficult to disentangle since both interact. Sometimes cumulative effects on learning can be observed when the educational goals of family and school fit together. This may be one reason for the higher achievement of Asian as compared with North American students (Stevenson 1988). For example, in Japan and Korea, teachers and mothers share the same educational values and coordinate informal and formal education.

Transfer of education between different contexts is easier when the same goals are functional. For example, the traditional Quranic education attempts to train memorizing by teaching fixed formulas, thus providing elements of social and cognitive skills required by modern schooling (Wagner 1988).

Negative effects on learning occur in the case of conflicting or nonmatching educational goals, e.g., in the case of involuntary acculturation when children from a minority group attend a majority-group school. The attainment of certain educational goals (e.g., acculturation, achievement) profits from the coordination of informal and formal education by cumulating their functional properties.

The effects of formal or informal education or their combination differ according to developmental age and depend on the person, the environmental conditions, and the adaptive function of the specific skill. According to studies by Wagner and Spratt (1987) language background and preschool experience have different effects on the reading acquisition of rural and urban Moroccan children in the first year of primary school. 'Modern' and 'traditional' preschooling need not differ with respect to higher level reading measures. The traditional Quranic preschool can be beneficial for literacy acquisition in Arabic. However, differences in literacy between urban and rural (or Arabicspeaking and Berber-speaking) children in Morocco caused by maternal language and preschooling could not be eliminated by mainstreaming modern primary schools. The effects of an urban environment were longer lasting than those of language background and preschool experience. These studies are relevant for analyzing effects of multicultural education. 
Formal schooling can influence general and domainspecific skills (e.g., literacy, Iogical thinking). Studies on Quranic-schooled adults in Liberia which isolate the effects of schooling and literacy show that literacy increases specific memory skills but can be acquired without Western schooling (Scribner and Cole 1981). Formal schooling can profit from informal education in contexts which have practical significance for arithmetic skills. However, informally acquired arithmetic skills in comparison to school-based algorithms have their limits (for a review, see Segall et al. 1999).

\subsection{International Comparison of School Achievement}

Formal schooling usually follows the 'Western model,' giving preference to such cognitive skills that facilitate success in highly technological and scientifically structured environments.

The Program for International Student Assessment (PISA) aims to provide nationally representative data from OECD countries on 15-year-old students' knowledge and skills in mathematics, science, reading, and cross-curricular competencies. Three large-scale comparative studies (First, Second and Third Mathematics and Science Study; FIMS, SIMS, TIMSS) by the policy oriented International Association for the Evaluation of Educational Achievement (IEA) demonstrate significant differences in school achievement (for a review, see Baumert 1998). Even among societies with a common language (Switzerland, Germany, Austria), significant differences occurred. Comparisons of mathematical achievement demonstrate significantly higher achievement of Japanese and Taiwanese as compared with North American children (Stevenson and Stigler 1992). High-achieving students from Asia as compared with Germany and North America show better mathematical performance. The test scores of Chinese and Japanese students in mathematics and science are higher than those of their American peers at all age groups (Stevenson et al. 1993).

These differences are presumably related to several factors, including differences in educational systems, teaching and learning styles, time use, cultural values, and relations between informal and formal education (e.g., Stevenson 1988). East Asians place a higher value on education, focus on the role of effort in academic achievement, hold higher aspirations, devote more time in academic effort, and report more parental involvement in their children's academic work (Stevenson et al. 1993). Differences in cognitive skills can be mediated by motivational and socioemotional factors (Kornadt et al. 1980, Kornadt and Trommsdorff 1996). Whether these are also affected by education has to be studied in future research.

\section{Outlook}

An increasing number of studies include culture in educational research. However, systematic comparisons are rare. Also, results on effects of culture and education are not consistent. This is related to several problems.

One problem lies in the fact that the focus of research was on either informal or formal education as separate settings ignoring their specific and possibly cumulative effects. School quality, family, and peer groups interact in various ways depending on the cultural context, thus affecting development and learning (Chamoux 1986).

Another problem lies in the fact that possible effects of genetic dispositions have rarely been studied and the role of education often has been overestimated. Research in the tradition of the nature-nurture controversy focusing on either biological or environmental conditions ignore the role of the active, selfreflective person (the learner as the producer of his/her development). Future research should take into account the impact of genetic dispositions on the development of abilities and the readiness for learning certain skills, and on interactions between environment (education) and person (Weinert and Perner 1996).

A further theoretical and methodological problem is the validity of the data. This is partly due to experimental artifacts and the context dependence of the behavior studied. Also, much cross-cultural research is based on Western theories and methods without explicit reference to culture. Often the role of certain skills in a specific culture is neglected. The functional equivalence of variables and measurements needs to be ascertained for valid comparisons. Here problems of etic (comparative) and emic (culture-specific, indigenous) methods are to be solved. Both approaches are necessary to arrive at universal and culture-specific theorizing (Trommsdorff 1986, Segall et al. 1999).

Education research needs a solid theoretical frame. An eco-cultural approach seems promising since it relates cultural conditions to educational and psychological processes. One basic assumption is that in the case that educational goals and practices are relevant in a culture, one can expect qualified development of related skills. For example, in hunting as compared with agricultural societies, spatial skills are needed for survival; they are more valued and more efficiently learned. In some cultures, holistic rather than analytic problem solving and group discussion rather than individual reflection are valued; educational goals are defined accordingly (for a review, see Serpell and Hatano 1997). Comparative research on intelligence is another example of how the culture-specific meaning was clarified (for a review, see Berry 1984). Conceiving intelligence as the adaptation of mental activities to the environment requires culture-specific measures of 
'intelligent' action and appropriate educational conditions for its development.

An eco-cultural approach starts from the insider's understanding and specifies what has to be accomplished (in various domains of behavior) in order to live in a certain cultural context. This allows one to link cultural context and cognitive skills and to study indigenous actions as part of the respective culture and as an indicator of 'practical intelligence.' A 'practice theory of culture and cognition' attempts to analyze educational processes affecting cognitive skills (Wagner and Spratt 1987). Related research on "everyday cognition' follows the sociohistorical approach rooted in Vygotsky's writings (for a review, see Segall et al. 1999).

These approaches are linked to the theoretical framework of the developmental niche proposed by Super and Harkness (1997) who assume that three subsystems surround the child: the physical and social contexts in which the child lives, the cultural educational practices, and the psychological characteristics of the caretaker, including their ethnotheories.

The developmental niche adapts to social change and thus allows for adaptation on the individual level, including acculturation. This theorizing is related to Bronfenbrenner's work and the eco-cultural framework suggested by Segall et al. (1999).

These theoretical approaches assume that education is linked to the given context which provides constraints and resources for learning and development. This needs further empirical testing. Once a solid theory has been developed, problems of measurement and the application of education research will be more easily solved.

See also: American Studies: Education; Apprenticeship and School Learning; Comparative Research in Education: IEA Studies; Comparative Studies: Method and Design; Cross-cultural Psychology; Cross-cultural Research Methods; Cultural Diversity, Human Development, and Education; Education: Cultural and Religious Concepts; Latin American Studies: Education; Soviet Studies: Education

\section{Bibliography}

Baumert J 1998 Internationale Schulleistungsvergleiche. In: Rost D H (ed.) Handwörterbuch Pädagogische Psychologie, Beltz, Weinheim, Germany, pp. 219--25

Berry J W 1984 Toward a universal psychology of cognitive competence. International Journal of Psychology 19: 335-61

Bruner J 1996 The Culture of Educution. Harvard University Press, Cambridge, MA

Chamoux MN I986 Apprendre autrement: Aspects des pédagogies dites informelles chez les Indiens du Mexique. In: Rossel P (ed.) Demain l'Artisanat? Presses Universitaires de France, Paris, pp. 21I-335
Delbos G, Jorion P 1984 La Transmission des Savoirs. Maison des Sciences de l'Homme, Paris

Désalmand P 1983 Histoire de I'Éducation en Côte d'hoire. CEDA, Abidjan, Ivory Coast, Vol. 1

Greenfield P, Lave J 1982 Cognitive aspects of informal education. In: Wagner D A, Stevenson H W (eds.) Cultural Perspectives on Child Development. Freeman, San Francisco, pp. 181-207

Kagitçibasi C 1996 Family and Human Developnent Across Cultures: A View from the Other Side. Erlbaum, Hillsdale, NJ

Kornadt H-J, Eckensberger L H, Emminghaus W B 1980 Crosscultural research on motivation and its contribution to a general theory of motivation. In: Triandis $\mathrm{H} \mathrm{C}$, Lonner W (eds.) Handhook of Cross-cultural Psychology: Vol. 3. Basic Processes. Allyn and Bacon, Boston, pp. 223-321

Kornadt H-J, Trommsdorff G 1996 Cross-cultural approaches to human development. In: DeCorte E, Weinert F E (eds.) The Encyclopedia of Developmental and Instructional Psychology. Pergamon, Oxford, pp. 51-5

Nyerere J M 1967 Education for Self-reliance. Government Printer, Dar es Sálaam, Tanzania

Rogoff B, Mistry J, Göncü A, Mosier C 1993 Guided participation in cultural activity by toddlers and caregivers. Monographs of the Society for Research in Child Development No. 50 (Serial No. 236)

Scribner S, Cole M 1981 The Psychology of Literacy. Harvard University Press, Cambridge, MA

Segall M H, Dasen P R, Berry J W, Poortinga Y H 1999 Human Behavior in Glohal Perspective: An Introduction to Crosscultural Psychology, 2nd edn. Allyn and Bacon, Boston

Serpell R, Hatano G 1997 Education, schooling, and literacy. In: Berry J W, Dasen P R, Saraswathi T S (eds.) Handbook of Cross-cultural Psychology: Vol. 2. Basic Processes and Human Development, 2nd edn. Allyn and Bacon, Boston, pp. 339-76

Stevenson H W 1988 Culture and schooling: Influences on cognitive development. In: Hetherington E M, Lerner R M, Perlmutter M (eds.) Child Development in Life-span Perspective. Erlbaum, Hillsdale, NJ, pp. 24I-58

Stevenson H W, Chen C, Lee S Y 1993 Mathematics achievement of Chinese, Japanese, and American children: Ten years later. Science 259: 53-8

Stevenson H W, Stigler J W 1992 The Learning Gap: Why Our Schools are Failing and What We Can Learn from Japanese and Chinese Education. Summit Books, New York

Super C M, Harkness S 1997 The cultural structuring of child development. In: Berry J W, Dasen P R, Saraswathi T S (eds.) Handbook of Cross-cultural Psychology: Vol. 2. Basic Processes and Human Development, 2nd edn. Allyn and Bacon, Boston, pp. 1-39

Trommsdorff G 1986 German cross-cultural psychology. German Journal of Psychology 10: 240-66

Wagner D A 1988 'Appropriate education' and literacy in the Third World. In: Dasen P R, Berry J W, Sartorius N (eds.) Health and Cross-cultural Psychology: Toward Applications. Sage, Newbury Park, CA, pp. 93-111

Wagner D A, Spratt JE 1987 Cognitive consequences of contrasting pedagogies: The effects of Quranic preschooling in Morocco. Child Development 58: 1207-19

Weinert FE, Perner J 1996 Cognitive development. In: Magnusson D (ed.) The Lifespan Development of Individuals: Behavioral, Neurohiological, and Psychosocial Perspectives. Cambridge University Press, New York, pp. 207-22

G. Trommsdorff and P. Dasen 